\title{
The role of mechanical testing in additive manufacturing: review
}

\author{
Venkesh Agarwal $^{1}$, Samidha Jawade ${ }^{2}$, Sagar Atre ${ }^{3}$, Omkar Kulkarni ${ }^{4}$ \\ School of Mechanical Engineering, Dr. Vishwanath Karad MIT World Peace University, Pune, 411038, \\ Maharashtra, India \\ ${ }^{1}$ Corresponding author \\ E-mail: ${ }^{1}$ venkesh1611@gmail.com, ${ }^{2}$ samidha.jawade@mitwpu.edu.in, ${ }^{3}$ sagar.atre@mitwpu.edu.in, \\ 4omkar.kulkarni@mitwpu.edu.in
}

Received 15 October 2021; received in revised form 26 November 2021; accepted 22 December 2021 DOI https://doi.org/10.21595/msea.2021.22258

Check for updates

Copyright $\mathbb{C} 2021$ Venkesh Agarwal, et al. This is an open access article distributed under the Creative Commons Attribution License, which permits unrestricted use, distribution, and reproduction in any medium, provided the original work is properly cited.

\begin{abstract}
Additive Manufacturing has become a new era of manufacturing technology that goes beyond traditional subtractive manufacturing. It is based on layer-by-layer material deposition technology. Additive manufacturing technology is widely used due to its various advantages such as accurate production in a short time, required product design and complexity, easy operation, rapid prototyping, etc. It is widely used in automobile industry, oil and electric power industry, aerospace industry, biomedical applications and many more. Mechanical testing plays an important role in understanding the complex relationships between basic process parameters, defects, and the final product of the AM process. Mechanical testing such as tensile testing, fatigue testing, torsion testing, hardness and impact tests etc. are crucial to determine various performance parameters of the component of product. Owing to increasing applications of additive manufacturing in various fields it is important to analyse the components produced for their mechanical performance and hence mechanical testing plays a very important role in additive manufacturing. This paper aims to review the various mechanical testing performed in the area of additive manufacture and available published data on the mechanical properties of additively manufactured components. This paper on AM processes discusses the mechanical properties of materials and current research.
\end{abstract}

Keywords: additive manufacturing, mechanical properties, fracture, fatigue, tensile, hardness test, mechanical testing.

\section{Introduction}

Additive Manufacturing (AM), also known as 3D printing, uses layer-by-layer material deposition techniques to build parts from CAD-generated 3D models. This manufacturing technology enables the production of jointless products or components with minimal post-treatment requirements and minimal material waste. AM was developed by Chuck Hull in 1983 which later came to be known as stereolithography. Computer Aided Design is used to generate a $3 \mathrm{D}$ model of the product to be $3 \mathrm{D}$ printed and is then translated into a model data. The printer then slices the data into various dimensional planes which is instrumental in instructing the deposition of material layer by layer. Fig. 1 [32] shows the general procedure followed in producing components through $3 \mathrm{D}$ printing. $3 \mathrm{D}$ printing has become a popular and viable option in many disciplines and many industries. Compared to traditional manufacturing methods, this method has many advantages such as accurate manufacturing in a short time, required design and product complexity, easy operation, rapid prototyping, and reduced material costs. Significantly accelerate product development and market entry, enabling agile product customization and feature integration faster and at lower cost. ASTM International's Technical Committee has finally properly defined these processes as Additive Manufacturing (AM). According to ISO/ASTM 52900-2015, There are seven additive manufacturing production techniques. Each varies due to materials, layering, and machine technology needed. Fig. 2 shows the types of Additive manufacturing process. 


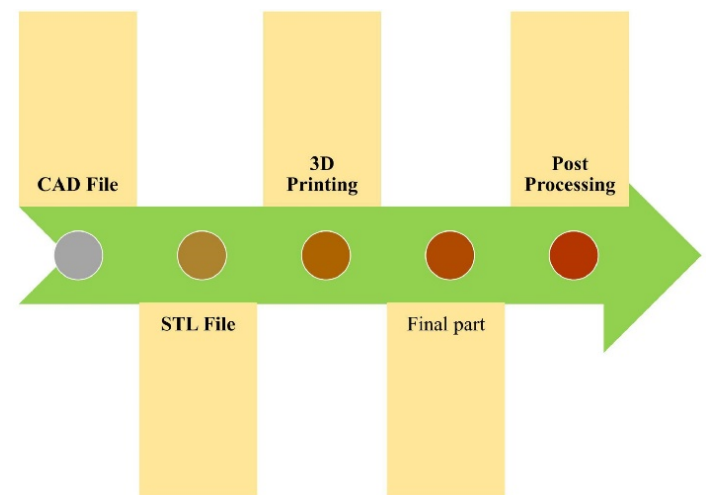

Fig. 1. Procedure followed in 3D printing, adapted from [32]

3D printing components are being increasingly used in various industries and fields. It finds large scale applications in aerospace, biomedical industry, automobile industry, oil and electric power industry. Advantages such as lower material wastage, lower costs, reduced post processing of components and easy manufacturing of very complex geometries makes $3 \mathrm{D}$ printing a very popular choice. In order to provide the required reliability in these major and serious applications that can have serious implications due to failure it is very crucial to analyse these $3 \mathrm{D}$ printed components for their mechanical performance. For example, in automobile applications there are often sudden impacts on various parts which can be 3D printed, in order to replace the conventionally manufactured parts by $3 \mathrm{D}$ printed parts it is necessary that these $3 \mathrm{D}$ parts should be more than or at the least equally reliable as the conventionally manufactured parts. Mechanical testing such as tensile testing to determine the tensile strength of the components, fatigue test to determine the lifecycle of components before failure, hardness test, impact test for failure, torsion test to determine the threshold values, vibrational analysis etc. are important to determine the performance of the 3D printed components. This paper summarises the various processes used in $\mathrm{AM}$, materials and finally the types of testing that are critical in determining the performance of the components manufactured through AM.

\subsection{Types of additive manufacturing}

\subsubsection{Powder bed fusion}

The powder bed melting method (abbreviated as PBF) is a layered manufacturing process such as direct metal laser sintering (DMLS), selective laser sintering (SLS), selective thermal sintering (SHS), and electron beam melting (EBM). It is a widely used technology. Metal Laser Melting (DMLM). It uses an electron or laser beam to fuse together fine layers of material which are closely packed and spread on a platform and the following layers of material is applied on top of previous layers until the desired geometry of component is obtained. Powder Bed fusion method results in fine resolution and high quality of the component produced [32].

\subsubsection{Direct energy deposition}

Direct energy deposition technology uses concentrated thermal energy to melt a material by melting it as it is deposited. An electron beam gun or laser mounted on a 4-axis or 5-axis arm melts a raw material or powder of metal wire or filament. The process can be used with a wider variety of materials, including polymers, ceramics and metals. 


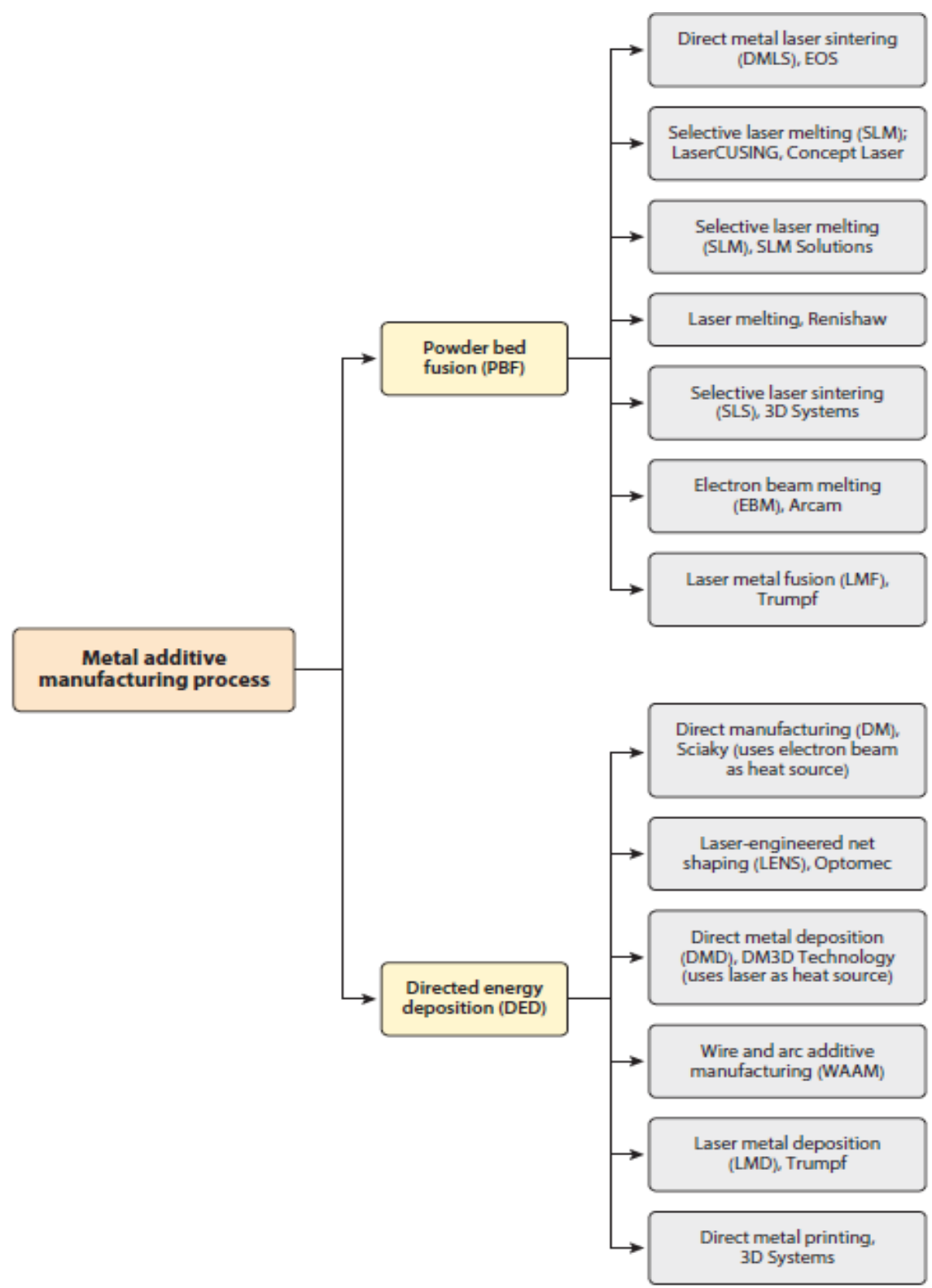

Fig. 2. Summary of metal additive manufacturing processes adapted from [29]

\subsubsection{Material extrusion}

Material extrusion is one of the most famous AM processes. The rolled polymer is extruded or stretched through a heating nozzle attached to the movable arm. The nozzles move horizontally, and the beds move vertically, so the molten material is stacked layer by layer. Proper bonding between layers is achieved by precise temperature control or the use of chemical adhesives. Benefits of this method are low cost and high speed.

\subsubsection{Stereolithography}

Stereolithography (abbreviated as SLA) is used to create models, prototypes, and patterns layer 
by layer by photopolymerization. Through the process of photopolymerization, light connects the molecular chains to form a polymer, forming the body of the model. It is the earliest AM process.

\subsubsection{Material jetting}

Material jetting is an AM method that uses an inkjet printhead to inject molten wax material onto a build platform The material cools and solidifies, so the layers can be layered on top of each other Printheads typically move the $x, y$, and $z$ axes back and forth to create $3 \mathrm{D}$ objects. The layers of this object will cure when cooled or cured by UV light. Benefits of this method are smooth surface finishing and multi-material printing.

\subsubsection{Binder jetting}

The binder injection method is similar to the material injection process, except that the printhead alternates between powder material layers and liquid behaviour layers. Inkjet printheads apply a liquid binder to a thin layer of powder. You can build parts layer by layer by gluing particles together. Binder injection technology is suitable for making components with different material types and range of colours.

\subsubsection{Sheet lamination}

Laminate manufacturing (LOM) and ultrasonic additive manufacturing (UAM) are two methods of sheet laminating. LOM uses alternating layers of paper and adhesive, and UAM uses thin metal plates that are ultrasonically bonded. LOM is great for creating objects that are ideal for visual or aesthetic modeling. Benefits of this method are low cost and high speed.

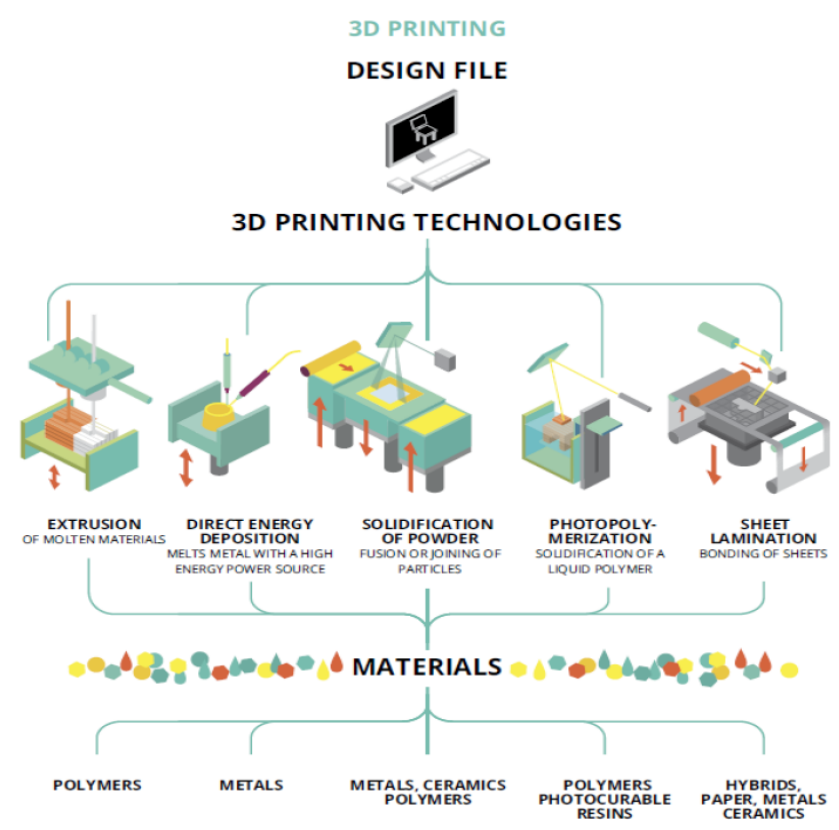

Fig. 3. Materials used in additive manufacturing [30]

\subsection{The material used in AM}

There are three types of materials available for additive manufacturing: polymer, ceramic, and metal. All seven processes of AM make use of these materials, polymers are most popularly used and certain additive manufacturing techniques allow themselves towards the use of certain 
materials over others. A huge variety of materials can be utilized for 3D printing, but metals are popularly used due to their extensive use in industrial and consumer appliances. Traditionally, the aerospace industry used advanced and costly materials like titanium and nickel alloys, which are difficult to manufacture and create a large amount of waste. Materials are often manufactured in the form of powder or wire feedstock. Other materials used include adhesive papers, paper, chocolate, and polymer/adhesive sheets for LOM. Fig. 3 and Table 1 shows the materials used in Additive manufacturing.

Table 1. Summary of various materials used in different process

\begin{tabular}{|c|c|c|}
\hline Sr.no. & Material category & Examples \\
\hline \multirow{9}{*}{1} & \multirow{9}{*}{ Polymers } & ABS (Acrylonitrile butadiene styrene) \\
\hline & & PLA (polylactide), including soft PLA \\
\hline & & $\mathrm{PC}$ (polycarbonate) \\
\hline & & Polyamide (Nylon) \\
\hline & & Nylon 12 (Tensile strength $45 \mathrm{MPa}$ ) \\
\hline & & Glass-filled nylon (12.48 MPa) \\
\hline & & Epoxy resin \\
\hline & & Wax \\
\hline & & Photopolymer resins \\
\hline \multirow{6}{*}{2} & \multirow{6}{*}{ Metals } & Maraging steel 1.2709 (Tensile Strength $1100 \mathrm{MPa}$ ) \\
\hline & & Titanium alloy Ti6AI4V (Tensile Strength $1150 \mathrm{MPa}$ ) \\
\hline & & 15-5ph stainless steel (Tensile Strength $1150 \mathrm{MPa})$ \\
\hline & & Cobalt chrome alloy, Co28Cr6Mo (Tensile Strength $1300 \mathrm{MPa}$ ) \\
\hline & & Aluminium AlSi10Mg (Tensile Strength $445 \mathrm{MPa}$ ) \\
\hline & & Gold and Silver \\
\hline \multirow{3}{*}{3} & \multirow{3}{*}{ Ceramics } & Silica/Glass \\
\hline & & Porcelain \\
\hline & & Silicon-Carbide \\
\hline
\end{tabular}

\section{Challenges for mechanical property characterization}

AM offers the opportunity for a rapid transition from design to product, especially for parts that are difficult or impossible to machine, but predicting mechanical properties remains a challenge. The difference between the AM process and the traditional process is that not all materials are melted and homogenized. The AM process of depositing material layers creates anisotropy and residual stress in the part. This is a big challenge. Researchers need to establish standardized methods for determining material properties based on specially designed AM treatments. Peer-reviewed literature is beginning to emphasize the complexity of associating mechanical properties with various process parameters. This issue is important to AM's success as a major manufacturing process, but there is not much literature available in this area. Research is moving towards a better understanding of raw material microstructure, material fusion and process parameters. Researchers try to find out the correlation between raw material, microstructure, material fusion process parameters and mechanical properties. Modelling is used to understand the relationship between anisotropic properties and AM products. Much work needs to be done to facilitate current research towards industry-related AM component testing. In this article, we will review the various mechanical tests performed on the samples created by AM. Table 2 shows Summary of various testing methods for AM components.

\section{Types of testing}

Mechanical properties can be categorized into static properties and dynamic properties. Static properties deal largely with tensile, torsion, hardness and impact properties of material. Dynamic properties deal largely with high and low fatigue cycles and creep cycles. Before employing the additively manufactured components in applications, a thorough round of testing is crucial to carry 
out on the component to ensure that each component meets t- he safety performance and quality standards. A wide range of testing is performed which is as follows.

Table 2. Summary of various testing methods for AM component

\begin{tabular}{|c|c|c|}
\hline Sr. No & Name of testing & Applications \\
\hline 1 & $\begin{array}{l}\text { Chemical } \\
\text { Analysis }\end{array}$ & $\begin{array}{l}\text { Various AM technologies use the powder form of material for } \\
\text { manufacturing; hence it becomes essential to understand and test the } \\
\text { chemical properties of these powders about specific requirements }\end{array}$ \\
\hline 2 & $\begin{array}{l}\text { Mechanical } \\
\text { Testing }\end{array}$ & $\begin{array}{l}\text { The performance characteristics of the components can be determined using } \\
\text { mechanical testing. These mechanical testing are performed according to } \\
\text { the ASTM standards to determine various factors. Widely performed } \\
\text { mechanical tests are- Tensile, hardness, Fatigue, Vibrational Analysis etc. }\end{array}$ \\
\hline 3 & $\begin{array}{l}\text { Metallurgical } \\
\text { Analysis }\end{array}$ & $\begin{array}{l}\text { To understanding the effects of build direction, process variables and } \\
\text { design, metallurgists utilize techniques ranging from optical microscopy } \\
\text { and SEM-EDS analysis to electron microprobe and advanced surface } \\
\text { analysis techniques. For Examples: } \\
\text { 1) Post-processing assessment } \\
\text { 2) Porosity evaluation } \\
\text { 3) Characterization on the interface layer } \\
\text { 4) Particle shedding analysis } \\
\text { 5) Microstructural characterization }\end{array}$ \\
\hline 4 & $\begin{array}{l}\text { Powders } \\
\text { Evaluation }\end{array}$ & $\begin{array}{l}\text { The product quality and operational efficiencies are highly dependent on the } \\
\text { characteristics of additive manufacturing powders. } \\
\text { 1) Particle Size Distribution } \\
\text { 2) Morphology } \\
\text { 3) Flow, quantitative shape analysis } \\
\text { 4) Powder imaging, density }\end{array}$ \\
\hline 5 & NDT & $\begin{array}{l}\text { 1) Computed tomography } \\
\text { 2) White light interferometry } \\
\text { 3) Surface profilometry } \\
\text { 4) Dimensional validation }\end{array}$ \\
\hline
\end{tabular}

\section{Overview of mechanical testing used for AM component}

\section{Different types of mechanical testing used to predict the performance of AM components}

\subsection{Tensile testing}

Additively manufactured components find a wide range of applications in industries like aerospace, defence, automotive, healthcare, oil and are exposed to various loading conditions. Tensile testing becomes crucial to determine the behaviour of these materials and the subsequent components under the action of load. This testing will provide insights into the mechanical performance of a $3 \mathrm{~d}$ printed material. Tensile testing is most often performed per ASTM standards. In the tensile testing of $3 \mathrm{~d}$ printed materials force, displacement and strain are measured and stress-strain characteristics are plotted. Generally, properties like ultimate tensile strength, elongation and elastic modulus are determined to understand the mechanical behaviour under loading conditions.

\subsection{Fatigue testing}

Generally, the purpose of fatigue testing is to determine the expected life of a material that is repeatedly loaded, but fatigue strength and crack resistance are also commonly required value. Fatigue test is used for the determination of the maximum load that a sample can withstand for a specified number of cycles. These properties are very important in any industry where the material fluctuates rather than the constant force. Most fatigue studies of AM materials are empirical. 
Defects play an important role in controlling the fatigue behaviour of AM materials. Almost all AM Metal fatigue data is generated under simple geometry and constant amplitude loads.

\subsection{Vibrational analysis}

Throughout the printing process, there are vibrations in the printer which depends upon various factors such as the structure of the printer, nozzle types, processing speeds, orientation of product etc. The vibrations produced in $3 \mathrm{~d}$ printers are forced vibrations. Neglecting these vibrational properties can lead to catastrophic failure of components produced through $3 \mathrm{~d}$ printed technology and hence it becomes essential to control these vibrations to obtain better mechanical properties of printed components. Vibration analysis/testing was sued for metallic as well as for non-metallic materials also.

Table 3. Summary of various Mechanical testing methods for AM component

\begin{tabular}{|c|c|c|c|}
\hline Machine types & Materials & Test & References \\
\hline EOS/laser-melted PBF & Ti-6Al-4V & Tensile & 4 \\
\hline $\begin{array}{c}\text { Renishaw } \\
\text { AM250/laser-melted } \\
\text { PBF }\end{array}$ & Ti-6Al-4V & Tensile & 5 \\
\hline $\begin{array}{l}\text { SLM250/laser-melted } \\
\text { PBF }\end{array}$ & Ti-6Al-4V & Tensile & 6 \\
\hline $\begin{array}{l}\text { EOS M270/laser- } \\
\text { melted PBF }\end{array}$ & Ti-6Al-4V & Tensile & 7 \\
\hline SLM250HL / PBF & TNM (Ti- Al-Nb-Mo) & Tensile & 8 \\
\hline EBM TiAl & EBM TiAl & Tensile & 9 \\
\hline EOS M280 IN718 & EOS M280 IN718 & Tensile & 10 \\
\hline SLM & IN718 & Tensile & 11 \\
\hline Arcam A2X & Ti4822 & Fatigue test & 12 \\
\hline Laser melting/PBF & Ti-6Al-4V & Fatigue test & 13 \\
\hline EBM & Ti-6Al-4V & Fatigue test & 14 \\
\hline PBM/SLM & Ti-6Al-4V & Fatigue test & 15 \\
\hline SLM $250 \mathrm{HL}$ & stainless steel 316L & Fatigue test & 16 \\
\hline SLM & $316 \mathrm{~L}, 15-5 \mathrm{PH}$ & Fatigue test & 17 \\
\hline FDM & $\begin{array}{l}\text { Acrylonitrile butadiene styrene } \\
\text { (ABS) }\end{array}$ & Fatigue test & 18 \\
\hline FDM & $\begin{array}{c}\text { Polymer Matrix Composite } \\
\text { Materials, CARBON FIBER } \\
\text { NYLON }\end{array}$ & Fatigue test & 19 \\
\hline FDM & $\begin{array}{l}\text { Polyethylene terephthalate Glycol } \\
\text { (PET-G) }\end{array}$ & Vibration analysis & 26 \\
\hline FDM & $\begin{array}{l}\text { ABS (Acrylonitrile butadiene } \\
\text { styrene) plastic }\end{array}$ & Vibration analysis & 24 \\
\hline FDM & Polylactic acid (PLA) & Vibration analysis & 33 \\
\hline EOSM250 & 4340 & Hardness and Tensile & 21 \\
\hline Arcam S12 & IN625 & Hardness and tensile & 22 \\
\hline SLM & Al-Si-10Mg & Hardness and tensile & 23 \\
\hline SLM & CoCrMo & Hardness and Tensile & 13 \\
\hline SLM & AZ91D & Hardness and Tensile & 14 \\
\hline Arcam A2X & Ti4822 & Fracture toughness & 24 \\
\hline SLM/SLM MTT250 & Ti-6Al-4V & Fracture toughness & 25 \\
\hline
\end{tabular}

\section{Conclusions}

This article reviews the latest techniques of additive manufacturing for with the focus on the major processes, microstructures and mechanical properties. The most commonly used AM 
techniques which are powder bed fusion, direct energy deposition, metal binder jetting, and sheet lamination, are presented in this article. For each of these techniques, the materials are discussed with respect to their mechanical properties. Table 3 outlines the mechanical properties that are typically generated in the mechanical characterization of materials based on their respective application. Following this scope of study, this review article outlines the available published data for materials used in AM for currently available AM process categories. Albeit the scope of already studied and published mechanical properties has not covered the complete stretch of those shown in Table 3, a part of the mechanical properties reported for the metallic systems approach and sometimes surpass the properties obtained on analogous materials which are conventionally processed. Comparatively less published articles and data are available on standard samples for vibrational analysis, hardness, low cycle fatigue, fatigue crack growth, fracture toughness, and multiaxial testing. However, these goals can be achieved through a more detailed understanding of the fundamental processing-structure-property relationships possible with this new emerging technology.

\section{Future scope}

There is a substantial scope of investigation on several topics. The various AM processing parameters such as parts microstructures, mechanical properties and their interrelations are still not fully conceived. To enhance the understanding, theoretical studies with the help of AM process modelling can be useful. These theoretical studies could include heat and mass transfer, melting pool prediction, residual stress and distortion evolution, atomistic diffusion, densification, phase change, etc. These models are important to fully understand the relation of structure-property. They can also be used to prognosticate as well as optimize the physical and mechanical properties, and at the same time generate strategies for AM materials design or inverse design. Another potential research direction of AM systems is production efficiency. Higher energy power or faster scanning speed will improve the production rate, but the product quality might get compromised because of variations in microstructures. To address this problem, optimization of process parameters is required for the design and application of AM techniques. Finally, the fabricated material property database and the standards are still being developed. It is still an ongoing effort to establish a comprehensive database to ensure the quality consistency of AM products.

\section{References}

[1] Y. Zhang et al., "Additive manufacturing of metallic materials: a review," Journal of Materials Engineering and Performance, Vol. 27, No. 1, pp. 1-13, Jan. 2018, https://doi.org/10.1007/s11665017-2747-y

[2] T. Duda and L. V. Raghavan, "3D metal printing technology," IFAC-PapersOnLine, Vol. 49, No. 29, pp. 103-110, 2016, https://doi.org/10.1016/j.ifacol.2016.11.111

[3] J. M. Wilson, C. Piya, Y. C. Shin, F. Zhao, and K. Ramani, "Remanufacturing of turbine blades by laser direct deposition with its energy and environmental impact analysis," Journal of Cleaner Production, Vol. 80, pp. 170-178, Oct. 2014, https://doi.org/10.1016/j.jclepro.2014.05.084

[4] H. Gong, K. Rafi, H. Gu, G. D. Janaki Ram, T. Starr, and B. Stucker, "Influence of defects on mechanical properties of Ti-6Al-4V components produced by selective laser melting and electron beam melting," Materials and Design, Vol. 86, pp. 545-554, Dec. 2015, https://doi.org/10.1016/j.matdes.2015.07.147

[5] M. Simonelli, Y. Y. Tse, and C. Tuck, "Effect of the build orientation on the mechanical properties and fracture modes of SLM Ti-6Al-4V," Materials Science and Engineering: A, Vol. 616, pp. 1-11, Oct. 2014, https://doi.org/10.1016/j.msea.2014.07.086

[6] S. Leuders et al., "On the mechanical behaviour of titanium alloy TiAl6V4 manufactured by selective laser melting: Fatigue resistance and crack growth performance," International Journal of Fatigue, Vol. 48, pp. 300-307, Mar. 2013, https://doi.org/10.1016/j.ijfatigue.2012.11.011

[7] H. K. Rafi, N. V. Karthik, H. Gong, T. L. Starr, and B. E. Stucker, "Microstructures and mechanical properties of Ti6Al4V parts fabricated by selective laser melting and electron beam melting," Journal 
of Materials Engineering and Performance, Vol. 22, No. 12, pp. 3872-3883, Dec. 2013, https://doi.org/10.1007/s11665-013-0658-0

[8] L. Löber, F. P. Schimansky, U. Kühn, F. Pyczak, and J. Eckert, "Selective laser melting of a betasolidifying TNM-B1 titanium aluminide alloy," Journal of Materials Processing Technology, Vol. 214, No. 9, pp. 1852-1860, Sep. 2014, https://doi.org/10.1016\%2fj.jmatprotec.2014.04.002

[9] L. Loeber et al., "Comparison off selective laser and electron beam melted titanium aluminides," in Solid Freeform Fabrication Proceedings, pp. 547-56, 2011, https://doi.org/10.26153/tsw/15316

[10] O. Scott-Emuakpor, J. Schwartz, T. George, C. Holycross, C. Cross, and J. Slater, "Bending fatigue life characterisation of direct metal laser sintering nickel alloy 718," Fatigue and Fracture of Engineering Materials and Structures, Vol. 38, No. 9, pp. 1105-1117, Sep. 2015, https://doi.org/10.1111/ffe.12286

[11] J. Strößner, M. Terock, and U. Glatzel, "Mechanical and microstructural investigation of nickel-based superalloy IN718 manufactured by selective laser melting (SLM)," Advanced Engineering Materials, Vol. 17, No. 8, pp. 1099-1105, Aug. 2015, https://doi.org/10.1002/adem.201500158

[12] I. Tolosa, F. Garciandía, F. Zubiri, F. Zapirain, and A. Esnaola, "Study of mechanical properties of AISI 316 stainless steel processed by "selective laser melting", following different manufacturing strategies," The International Journal of Advanced Manufacturing Technology, Vol. 51, No. 5-8, pp. 639-647, Nov. 2010, https://doi.org/10.1007/s00170-010-2631-5

[13] M. Seifi, I. Ghamarian, P. Samimi, U. Ackelid, P. Collins, and J. Lewandowski, "Microstructure and mechanical properties of Ti-48Al-2Cr-2 $\mathrm{Nb}$ manufactured via electron beam melting," in Proceedings of the 13th World Conference on Titanium, pp. 1317-1322, May 2016, https://doi.org/10.1002/9781119296126.ch223

[14] V. Cain, L. Thijs, J. van Humbeeck, B. van Hooreweder, and R. Knutsen, "Crack propagation and fracture toughness of Ti6Al4V alloy produced by selective laser melting," Additive Manufacturing, Vol. 5, pp. 68-76, Jan. 2015, https://doi.org/10.1016/j.addma.2014.12.006

[15] M. Seifi, D. Christiansen, J. Beuth, O. Harrysson, and J. J. Lewandowski, "Process mapping, fracture and fatigue behavior of Ti-6Al-4V produced by Ebm additive manufacturing," in Proceedings of the 13th World Conference on Titanium, pp. 1373-1377, May 2016, https://doi.org/10.1002/9781119296126.ch232

[16] L. E. Murr et al., "Metal fabrication by additive manufacturing using laser and electron beam melting technologies," Journal of Materials Science and Technology, Vol. 28, No. 1, pp. 1-14, Jan. 2012, https://doi.org/10.1016/s1005-0302(12)60016-4

[17] P. C. Collins et al., "Progress toward an integration of process-structure-property-performance models for “Three-Dimensional (3-D) Printing”" of titanium alloys," JOM, Vol. 66, No. 7, pp. 1299-1309, Jul. 2014, https://doi.org/10.1007/s11837-014-1007-y

[18] J. Yu, M. Rombouts, G. Maes, and F. Motmans, "Material properties of Ti6Al4V parts produced by laser metal deposition," Physics Procedia, Vol. 39, pp. 416-424, 2012, https://doi.org/10.1016/j.phpro.2012.10.056

[19] M. Seifi, A. Salem, J. Beuth, O. Harrysson, and J. J. Lewandowski, "Overview of materials qualification needs for metal additive manufacturing," JOM, Vol. 68, No. 3, pp. 747-764, Mar. 2016, https://doi.org/10.1007/s11837-015-1810-0

[20] P. C. Collins, D. A. Brice, P. Samimi, I. Ghamarian, and H. L. Fraser, "Microstructural control of additively manufactured metallic materials," Annual Review of Materials Research, Vol. 46, No. 1, pp. 63-91, Jul. 2016, https://doi.org/10.1146/annurev-matsci-070115-031816

[21] E. Jelis, M. Clemente, S. Kerwien, N. M. Ravindra, and M. R. Hespos, "Metallurgical and mechanical evaluation of 4340 steel produced by direct metal laser sintering," JOM, Vol. 67, No. 3, pp. 582-589, Mar. 2015, https://doi.org/10.1007/s11837-014-1273-8

[22] L. E. Murr et al., "Microstructural architecture, microstructures, and mechanical properties for a nickel-base superalloy fabricated by electron beam melting," Metallurgical and Materials Transactions A, Vol. 42, No. 11, pp. 3491-3508, Nov. 2011, https://doi.org/10.1007/s11661-011-07482

[23] K. Kempen, L. Thijs, J. van Humbeeck, and J.-P. Kruth, "Processing AlSi10Mg by selective laser melting: parameter optimisation and material characterisation," Materials Science and Technology, Vol. 31, No. 8, pp. 917-923, Jun. 2015, https://doi.org/10.1179/1743284714y.0000000702

[24] C. Song, Y. Yang, Y. Wang, D. Wang, and J. Yu, "Research on rapid manufacturing of CoCrMo alloy femoral component based on selective laser melting," The International Journal of Advanced 
Manufacturing Technology, Vol. 75, No. 1-4, pp. 445-453, Oct. 2014, https://doi.org/10.1007/s00170014-6150-7

[25] K. Wei, M. Gao, Z. Wang, and X. Zeng, "Effect of energy input on formability, microstructure and mechanical properties of selective laser melted AZ91D magnesium alloy," Materials Science and Engineering: A, Vol. 611, pp. 212-222, Aug. 2014, https://doi.org/10.1016/j.msea.2014.05.092

[26] S. Krishna Chaitanya, Dr. K. Madhava Reddy, and Sai Naga Sri Harsha. C., "Vibration properties of $3 \mathrm{~d}$ printed/rapid prototype parts," International Journal of Innovative Research in Science, Engineering and Technology, Vol. 4, No. 5, pp. 4702-4608, 2015, https://doi.org/10.15680/ijirset.2015.0406087

[27] A. Srivastava, C. Gautam, N. Bhan, and R. Dayal, "Vibration analysis of cantilever shaped 3D printers," IOP Conference Series: Materials Science and Engineering, Vol. 594, No. 1, p. 012020, Aug. 2019, https://doi.org/10.1088/1757-899x/594/1/012020

[28] Menderes Kam, Hamit Saruhan, and Ahmet Ipekci, "Investigation the effects of 3d printer system vibrations on mechanical properties of the printed products," Sigma Journal of Engineering and Natural Sciences, Vol. 36, No. 3, pp. 655-666, Sep. 2018.

[29] R. Molaei and A. Fatemi, "Fatigue design with additive manufactured metals: issues to consider and perspective for future research," Procedia Engineering, Vol. 213, pp. 5-16, 2018, https://doi.org/10.1016/j.proeng.2018.02.002

[30] E. Uhlmann, G. Gerlitzky, and C. Fleck, "Fatigue behavior of additive manufactured parts in different process chains - an experimental study," in 2017 International Solid Freeform Fabrication Symposium, 2017.

[31] J. J. Lewandowski and M. Seifi, "Metal additive manufacturing: a review of mechanical properties," Annual Review of Materials Research, Vol. 46, No. 1, pp. 151-186, Jul. 2016, https://doi.org/10.1146/annurev-matsci-070115-032024

[32] A. Wijk and I. V. Wijk, 3D Printing with Biomaterials: Towards a Sustainable and Circular Economy. Burke: IOS Press, 2015.

[33] C. K. Yong, G. J. Gibbons, C. C. Wong, and G. West, "A critical review of the material characteristics of additive manufactured IN718 for high-temperature application," Metals, Vol. 10, No. 12, p. 1576, Nov. 2020, https://doi.org/10.3390/met10121576

[34] A. Jandyal, I. Chaturvedi, I. Wazir, A. Raina, and M. I. Ul Haq, "3D printing - a review of processes, materials and applications in industry 4.0," Sustainable Operations and Computers, Vol. 3, pp. 33-42, 2022, https://doi.org/10.1016/j.susoc.2021.09.004

[35] G. Li et al., "Effect of ultrasonic vibration on mechanical properties of 3D printing non-crystalline and semi-crystalline polymers," Materials, Vol. 11, No. 5, p. 826, May 2018, https://doi.org/10.3390/ma11050826

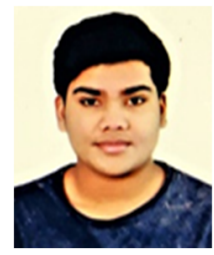

Venkesh Agarwal is a student of BTech Mechanical Engineering at Dr. Vishwanath Karad MIT World Peace University, Pune, 411038, Maharashtra, India. His current research interests include additive manufacturing, operations research, optimization and supply chain management.

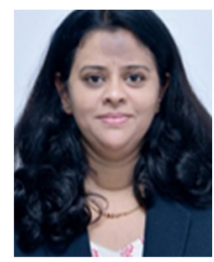

Samidha Jawade has received her master's degree in process metallurgy, currently pursuing her Ph.D. degree in mechanical engineering from MIT World Peace University from, Pune, Maharashtra. Now she works as Assistant Professor in Dr. Vishwanath Karad MIT World Peace University. Her current research includes composite materials and additive manufacturing. 
Sagar Atre is a research scholar at Dr. Vishwanath Karad MIT World Peace University, Pune, 411038, Maharashtra, India. His research interests include automotive technology.

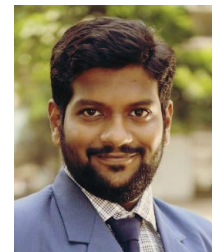

Omkar Kulkarni has received his master's degree in computer aided design, manufacture and engineering, currently pursuing his Ph.D. degree in mechanical engineering from MIT World Peace University from, Pune, Maharashtra. Now he works as Assistant Professor in Dr. Vishwanath Karad MIT World Peace University. His current research includes applications of nature inspired algorithm in mechanical applications and micro-forming of sheet metal. 